\title{
Reduction in Secretion of Very Low Density Lipoprotein-Triacylglycerol by a Matrix Metalloproteinase Inhibitor in a Rat Model of Diet-Induced Hypertriglyceridemia ${ }^{\mathbf{S}}$
}

\author{
Yoichi Kawashima, Yoshihiro Eguchi, Tohru Yamazaki, Minako Karahashi, Hiroshi Kawai, \\ and Naomi Kudo
}

Faculty of Pharmacy and Pharmaceutical Sciences, Josai University, Sakado, Saitama, Japan

Received November 2, 2017; accepted May 3, 2018

\section{ABSTRACT}

Matrix metalloproteinase inhibitors (MMPIs) reduced serum triacylglycerol (TAG) levels in streptozotocin-induced diabetic rats and Zucker fa/fa rats in our previous study. However, the mechanisms underlying TAG reduction by MMPIs remain unclear. The present study aimed to elucidate the mechanism by which F81-1144b, an MMPI, lowers serum TAG levels in an animal model of high-sucrose diet (HSD)-induced hypertriglyceridemia. F81-1144b was repeatedly administered to rats fed HSD, and its effects were evaluated on TAG levels in serum and the liver, very low density lipoprotein (VLDL) secretion, de novo fatty acid (FA) synthesis in the liver, and the expression of genes regulating the metabolism of FA, TAG, and VLDL in the liver and serum. F81-1144b lowered TAG levels in serum and the liver, VLDL-TAG secretion, de novo FA synthesis in the liver, and
\end{abstract}

serum levels of insulin and glucose. F81-1144b suppressed the expression of genes related to the de novo synthesis of FA and TAG, key proteins (lipin 1 and apolipoprotein CIII) responsible for VLDL metabolism, and sterol regulatory elementbinding protein-1c and carbohydrate response elementbinding protein. F81-1144b little affected the expression of genes related directly to the degradation of TAG or FA, but it upregulated that of gene for uncoupling protein 2 in the liver. These results suggest that MMPIs are a novel type of therapeutic agent for the treatment of hypertriglyceridemia, because the metabolic effects of F81-1144b expected from changes in the expression of genes regulating lipid metabolism would alter metabolism differently from those induced by fibrates, niacin, or $n-3$ FAs.

\section{Introduction}

Low density lipoprotein (LDL) has been firmly established as the primary atherogenic lipoprotein. However, even at low plasma-LDL levels among patients treated with statins, the high residual risk of cardiovascular disease (CVD) is not abrogated (Fruchart et al., 2008; Kearney et al., 2008). The independent relationship between plasma triacylglycerol (TAG) and the risk of future CVD events has remained controversial; however, recent studies demonstrated that elevated plasma TAG levels are strongly and independently associated with the risk of CVD (Harchaoui et al., 2009; Neil et al., 2010; Sarwar et al., 2010; Langsted et al., 2011; Nordestgaard and Varbo, 2014; Nordestgaard, 2016). A number of metabolic conditions are frequently associated with hypertriglyceridemia. The factors associated with increases

https://doi.org/10.1124/jpet.117.246165.

S This article has supplemental material available at jpet.aspetjournals.org. in plasma TAG levels are a genetic predisposition (such as familial hypertriglyceridemia and familial combined hyperlipidemia), diseases (such as insulin resistance, metabolic syndrome, type 2 diabetes, type 1 diabetes, and renal diseases), lifestyle factors (such as obesity, alcohol consumption, and a diet enriched with simple carbohydrates), and medications (such as estrogens) (Boullart et al., 2012). Very low density lipoprotein (VLDL) overproduction appears to be central to the pathophysiology of hypertriglyceridemia in an insulin-resistant state (Taskinen, 2003; Adiels et al., 2008). Hypertriglyceridemic subjects with more visceral fat storage have been reported to have larger TAG-enriched VLDL particles (Wang et al., 2011). In patients with hepatic steatosis, VLDL overproduction results from compensatory mechanisms for hepatic lipid overload, which ultimately increases the risk of developing hypertriglyceridemia and atherosclerosis (Chatrath et al., 2012). The aberrant metabolism of TAG-rich lipoproteins (TRL) (VLDL and chylomicrons) results in increased plasma TRL remnants and

ABBREVIATIONS: ACC1, acetyl-CoA carboxylase 1; ACLY, ATP-citrate lyase; ACSL, long-chain acyl-CoA synthetase; apo, apolipoprotein; ATGL, adipose triglyceride lipase; BSA, bovine serum albumin; CD36, fatty acid translocase; ChREBP, carbohydrate response element-binding protein; CPT1a, carnitine palmitoyltransferase 1a; CVD, cardiovascular disease; DGAT, acyl-CoA:diacylglycerol acyltransferase; FA, fatty acid; FAS, fatty acid synthase; GPAT, glycerol-3-phosphate acyltransferase; G6PD, glucose-6-phosphate dehydrogenase; HSD, high-sucrose diet; LDL, low density lipoprotein; LPL, lipoprotein lipase; ME1, malic enzyme 1; MMPI, matrix metalloproteinase inhibitor; MTP, microsomal triglyceride transfer protein; ND, normal diet; NEFA, non-esterified fatty acids; PPAR $\alpha$, peroxisome proliferator-activated receptor $\alpha$; SCD1, stearoyl-CoA desaturase 1; SREBP-1c, sterol regulatory element-binding protein-1c; TAG, triacylglycerol(s); TRL, triacylglycerol-rich lipoprotein; UCP2, uncoupling protein 2; VLDL, very low density lipoprotein. 
elevated small dense LDL, lipoprotein particles that are strongly associated with an increased risk of CVD (Miller et al., 2011). Under conditions of TRL overproduction and/or delayed clearance, TRL and/or TRL remnants formed during lipolysis are more likely to enter artery walls, causing foam cell formation and activating vascular cell inflammation (Nordestgaard et al., 1995; Schwartz and Reaven, 2012). Moreover, VLDL particles are larger and LDL particles are smaller in insulin-resistant states; LDL size is inversely associated with plasma TAG levels (Berneis and Krauss, 2002). Small dense LDL particles are retained for longer period of time in the circulation, are glycated and oxidized, and are prone to cross the endothelial surface, contributing to plaque formation. Thus, increased TRL remnants play a pivotal role in the pathophysiology of atherosclerosis, and thereby contribute to CVD (Chapman et al., 2011; Nordestgaard, 2016). In this context, the prevalence of elevated TRL is a major concern (Miller et al., 2011).

Fibrates, niacin, and $n-3$ fatty acids (FAs) are currently the first choice treatments for hypertriglyceridemia (Ito, 2015). The mechanistic actions of these agents markedly differ from each other. Considering the diversity in the pathogenesis of hypertriglyceridemia, the wide variety of agents available for selection to reduce plasma TAG is a therapeutic benefit. We previously demonstrated that among various metabolic conditions that are known to be associated with increases in serum TAG, the administration of matrix metalloproteinase inhibitors (MMPIs), the structures of which are similar to that of F81-1144b, reduced the serum levels of TAG, VLDL-TAG, and LDL-cholesterol, but not those of high density lipoproteincholesterol in streptozotocin-induced diabetic rats (a model of type 1 diabetes) and genetically obese Zucker fa / fa rats (a model of genetic obesity owing to a dysfunction in the actions of leptin) (Morikawa et al., 2007). In comparison with a population with hypertriglyceridemia attributed to these two metabolic disorders, however, in a population with hypertriglyceridemia that results from changes in dietary habits, a marked increase in dietary intake of fructose from sucrose and fructose-enriched sweeteners is considered to be much greater. Epidemiologic studies have shown that the consumption of sucrose or a mixture of glucose and fructose is associated with the occurrence of metabolic disorders including hypertriglyceridemia (Ouyang et al., 2008; Tappy and Lê, 2010). Nevertheless, no information is currently available on whether MMPIs reduce serum TAG in animal models with diet-induced hypertriglyceridemia, but not diabetes or obesity. Moreover, the mechanisms underlying MMPI-induced reductions in serum TAG remain unclear. In this context, the present study aimed 1) to investigate whether MMPIs suppress serum TAG levels in animals with high-sucrose diet (HSD)-induced hypertriglyceridemia and, if this is the case, 2) to elucidate the metabolic mechanism by which MMPIs reduce serum TAG levels.

\section{Materials and Methods}

Chemicals. The following materials were obtained from the indicated commercial sources: $\left[1-{ }^{14} \mathrm{C}\right]$ acetic acid $(2.035 \mathrm{TBq} / \mathrm{mol})$, [U- $\left.{ }^{14} \mathrm{C}\right]-$ glycerol-3-phosphate $(5.55 \mathrm{TBq} / \mathrm{mol})$, and $\left[1,3{ }^{3} \mathrm{H}\right]$ glycerol $(1480 \mathrm{TBq} / \mathrm{mol})$ (American Radiolabeled Chemicals, Inc., St. Louis, MO); acetyl-CoA, palmitoyl-CoA, glycerol-3-phosphate, Triton WR-1339, and bovine serum albumin (BSA) (MilliporeSigma, St. Louis, MO). F81-1144b, the structure

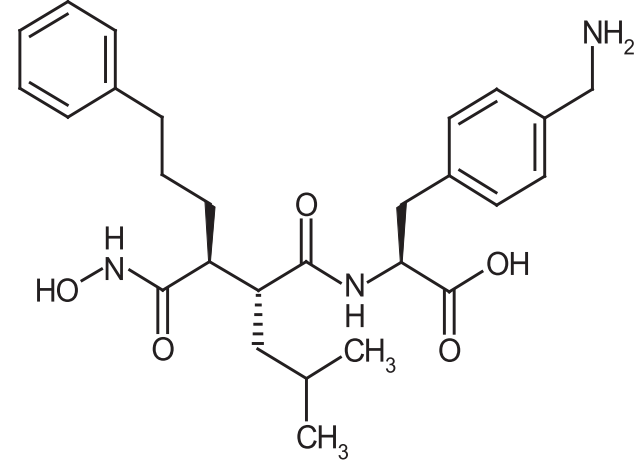

Fig. 1. Molecular structure of F81-1144b.

of which is shown in Fig. 1, was kindly provided by Daiichi Fine Chemical Co., Ltd. (Takaoka, Japan); F81-1144b is a subcutaneously active hydroxamic acid MMP inhibitor that exhibits potent activity against a number of MMPs, including MMP-1 $\left(\mathrm{IC}_{50}=5 \mathrm{nM}\right)$ and MMP-3 $\left(\mathrm{IC}_{50}=29 \mathrm{nM}\right)$ (Fujisawa et al., 2001).

Animals. All animal procedures were approved by the Institutional Animal Care Committee of Josai University in accordance with the Guidelines for the Proper Conduct of Animal Experiments (Science Council of Japan). Six-week-old male Wistar rats were purchased from SLC Inc. (Hamamatsu, Japan). Rats were acclimatized for 1 week on a standard rodent chow (CE-2; Clea Japan Inc., Tokyo, Japan).

Study Design. After acclimatization for 1 week, 7-week-old rats were divided into four groups. Group 1 was fed the standard diet for an additional 21 days [normal diet (ND)-fed rats]. Group 2 was fed HSD for 21 days. HSD (catalog No 960403; ICN Pharmaceuticals, Costa Mesa, CA) was purchased from Oriental Yeast Co. (Tokyo, Japan) and contained (by weight): 68\% sucrose, $8 \%$ cottonseed oil, 18\% milk casein, $2 \%$ beer yeast, and the required vitamins and minerals. Group 3 was maintained on HSD for 21 days and subcutaneously received F81-1144b at a dose of $50 \mathrm{mg} / \mathrm{kg}$ once a day for 7 days before being sacrificed. Group 4 was fed HSD for 21 days and subcutaneously received $\mathrm{F} 81-1144 \mathrm{~b}$ at a dose of $100 \mathrm{mg} / \mathrm{kg}$ once a day for 7 days before being sacrificed. F81-1144b was suspended in saline at a concentration of $50 \mathrm{mg} / \mathrm{ml}$. At the age of 10 weeks, rats were sacrificed in the fed state. Rats were anesthetized with diethyl ether, and blood was withdrawn from the inferior vena cava. The liver was rapidly removed, washed with ice-cold saline, and weighed. Two portions of the liver were frozen in liquid nitrogen and stored at $-80^{\circ} \mathrm{C}$ until the analysis of mRNA and acetyl-CoA. The remainder of the liver was used for a lipid analysis and the preparation of homogenates and microsomes. The parts of the liver that were used to prepare homogenates and microsomes were perfused with ice-cold saline.

Serum Clinical Chemistry. Serum was obtained from blood by centrifugation at $1200 \mathrm{~g}$ for 15 minutes. Serum TAG, total cholesterol, non-esterified fatty acids (NEFA), and glucose were measured using colorimetric enzymatic assay kits from Wako Pure Chemicals (Osaka, Japan). Serum insulin was measured using a rat RIA kit from MilliporeSigma (Billerica, MA).

Hepatic Lipid Analysis. After the addition of a known amount of triheptadecanoin as an internal standard, total lipids were extracted from liver homogenates by the reported method (Bligh and Dyer, 1959). Cholesteryl ester, TAG, diacylglycerol, free FA, and phospholipid were separated by thin-layer chromatography on silica gel $\mathrm{G}$ plates, which were developed with $n$-hexane/diethyl ether/acetic acid $(80: 30: 1, \mathrm{v} / \mathrm{v} / \mathrm{v})$. After visualization by spraying $0.001 \%(\mathrm{w} / \mathrm{v})$ primuline in $80 \%$ acetone, each region that corresponded to TAG and phospholipids on the plates was scraped off and transferred to tubes. A known amount of methyl heptadecanoate was added to the tubes containing phospholipids as an internal standard. TAG and phospholipids were extracted from silica gel as described previously (Imai 
TABLE 1

Sequences of primers used for real-time PCR

\begin{tabular}{|c|c|c|c|}
\hline Gene & Forward Primer $\left(5^{\prime}-3^{\prime}\right)$ & Reverse Primer $\left(5^{\prime}-3^{\prime}\right)$ & Accession No. \\
\hline Lpl & AGCGCTCCATCCATCTCTTCAT & TCAGGCAGAGCCCTTTCTCAA & NM_012598 \\
\hline Apoc3 3 & GACAATCGCTTCAAATCCCT & CGGCTCAAGAGTTGGTGTTG & NM_012501 \\
\hline Mtp & ACGTGGTATTCCCGCCTCA & CGTCAAAGCATTTCGTTCTCG & BC012686 \\
\hline Lipin1 & AGGGAGGGAGATGGTGGTTT & CTCTCCGGTATTGTGGCCCTT & NM_001012111 \\
\hline Apoa1 & GGCACCGAGCTTCACAAAAA & TGATCGCTGTAGAGCCCAAACT & NM_012738.1 \\
\hline Fas & CGCCGACCAGTATAAACCCA & GTTGTAATCGGCACCCAAGTC & M76767 \\
\hline Acc1 & AACGCCTTCACACCACCTTG & AGTCGCAGAAGCAGCCCAT & J03808 \\
\hline G6pd & CTTTGGACCCATCTGGAATCG & TCAAAATAGCCCCCACGACC & NM_017006 \\
\hline Acly & AAACTGTATCGCCCAGGCAGT & GTAACGCAGCACGTGATCCAT & J05210 \\
\hline$M e 1$ & ACAATACAGTTTGGCATTCCG & AGGATTCGCTCTCCATCAGTCA & \\
\hline Scd1 & TCACCTTGAGAGAAGAATTAGCA & TTCCCATTCCCTTCACTCTGA & J02585 \\
\hline Gpat1 & AGACACAGGCAGGGAATCCAC & AATTCCCGGAGAAGCCCAG & $\mathrm{AF} 021348$ \\
\hline Gpat4 & TTGGAGTCCTGGAATTTGCTGA & GGCTAATCCCTGTGAATGCCA & NM_001047849 \\
\hline Dgat1 & CCGTGGTATCCTGAATTGGT & GGCGCTTCTCAATCTGAAAT & NM_053437 \\
\hline Dgat2 & ATCTTCTCTGTCACCTGGCT & ACCTTTCTTGGGCGTGTTCC & NM 001012345 \\
\hline Cd36 & CGAAGGCTTGAATCCTACCG & TGTTGACCTGCAGTCGTTT & NM_031561 \\
\hline Fatp2 & TTCAACAGTGGCGATCTCCTG & ACCGGAAGGTGTCTCCAACT & NM_031736 \\
\hline Acsl1 & TCAGAGCAGTTCATCGGCATC & GTCGGTTCCAAGCGTGTCATA & NM 012820 \\
\hline Acsl5 & CAAACATGGCTGCTTTCCTCA & ACCCTGGACAAGCCTCTCAAA & NM_053607 \\
\hline Atgl & TCACCAACACCAGCATCCAA & TCCATCTCGGTAGCCCTGTTT & NM_001108509 \\
\hline Cgi58 & TGCATAGATGGCAACTCTGGC & ATACACATAATGCCCTGCCCC & NM_212524 \\
\hline Cpt1a & AAGGCAGCGTTCTTCGTGA & GTCAAAGCATCTTCCATGC & NM_031559 \\
\hline Mcad & CTTTGCCTCTATTGCGAAGGC & TCCGAAAATCTGCACAGCATC & J02791 \\
\hline Lcad & TGTATTGGTGCCATAGCCATGA & CCCAGACCTTTTGGCATTTGT & L11276 \\
\hline UCP2 & CAAGACCATTGCACGAGAGGA & CAGTTGACAATGGCATTTCGG & NM_019354.2 \\
\hline Srebp1c & GGAGCCATGGATTGCACATT & AGGAAGGCTTCCAGAGAGGA & AF286469 \\
\hline Chrebp & AATAGAGGAGCTCAATGCT & CCCAGAACTTCCAGTTGTGC & AB074517 \\
\hline Ppara & AATGCCCTCGAACTGGATGAC & CACAATCCCCTCCTGCAACTT & NM_013196 \\
\hline Lpk & TGTGTACCACCGCCAGTTGTT & AGCACTTGAAGGAAGCCTCCA & M17685 \\
\hline Acot1 & ACTACGACGACCTCCCCAAGA & TGGCCACGCAGGTAGTTCA & NM_031315.1 \\
\hline$\beta$-Actin & TGCAGAAGGAGATTACTGCC & CGCAGCTCAGTAACAGTCC & V01217 \\
\hline
\end{tabular}

et al., 1999). FA methyl esters were prepared using sodium methoxide/methanol. FA methyl esters were measured by gas-liquid chromatography (Shimadzu GC-2014; Shimadzu, Kyoto, Japan) as described previously (Yamazaki et al., 2014).

Acetyl-CoA Measurement in the Liver. Acetyl-CoA was extracted from one portion of the liver and measured enzymatically using a reported method (Decker, 1985).

Measurement of VLDL-TAG Secretion in HSD-Fed Rats in the Fed State. Rats that were maintained on HSD for 21 days were subcutaneously administered F81-1144b at a dose of $100 \mathrm{mg} / \mathrm{kg}$ once a day for 7 days before being killed at 10 weeks. Rats were anesthetized with urethane at a dose of $0.9 \mathrm{~g} / \mathrm{kg}$ and underwent surgical catheter implantation via the jugular vein (SP-31) and portal vein (SP-10). Rats were administered $\left[1,3-{ }^{3} \mathrm{H}\right]$ glycerol solution $(24.7 \mathrm{MBq} / 0.37 \mathrm{ml}$ saline per kilogram) via the portal vein, and Triton WR1339 solution $(600 \mathrm{mg} / 3 \mathrm{ml}$ saline per kilogram) was injected via the tail vein 15 minutes later. Triton WR1339 was used to inhibit lipoprotein lipase (LPL) (Millar et al., 2005). Blood samples were collected into heparinized tubes via the jugular vein 1 minute before and 30, 60, 90, and 120 minutes after the Triton WR1339 injection. Plasma samples were prepared by centrifugation at $3000 \mathrm{~g}$ for 5 minutes. Total lipids were extracted from plasma by the method of Bligh and Dyer (1959). TAG was separated by thin-layer chromatography on silica gel $G$ plates and then extracted from silica as described above. Radioactivity was measured using a liquid scintillation counter (Aloka LSC6100; Hitachi Ltd., Tokyo, Japan).

Measurement of In Vivo Synthesis of FA in the Liver. Hepatic FA synthesis was estimated by measuring the in vivo incorporation of $\left[1-{ }^{14} \mathrm{C}\right]$ acetic acid into FA in the liver according to the previously reported method (Sakurai et al., 1978) with some modifications. In brief, $\left[{ }^{14} \mathrm{C}\right]$ acetic acid was dissolved in saline $(370 \mathrm{kBq} / \mathrm{ml})$. Under anesthesia with diethyl ether, HSD-fed control rats and HSD-fed rats that had been treated daily with F81-1144b at a dose of 50 or $100 \mathrm{mg} / \mathrm{kg}$ for 7 days were intraperitoneally injected with $\left[{ }^{14} \mathrm{C}\right]$ acetic acid at a dose of $1.48 \mathrm{MBq} / 10 \mu \mathrm{mol} / 4 \mathrm{ml}$ saline per kilogram body weight. Ten minutes after the injection, livers were immediately isolated and snap-frozen in liquid nitrogen. Lipids were extracted from the liver (Bligh and Dyer, 1959). Extracted lipids were saponified with $10 \%$ methanolic $\mathrm{KOH}$ at $80^{\circ} \mathrm{C}$ for 60 minutes under a nitrogen atmosphere. After being diluted with water, unsaponifiable matter was extracted with $n$-hexane three times. The aqueous phase was acidified with $6 \mathrm{M} \mathrm{HCl}$, and FAs were extracted with $n$-hexane three times. FAs were mixed with scintillation fluid after drying down, and radioactivity was measured using a liquid scintillation counter.

Real-Time Quantitative PCR. Total RNA was isolated from liver tissues using the QIAzol reagent and RNeasy kit (QIAGEN, Hilden, Germany). cDNA was synthesized from $500 \mathrm{ng}$ of total RNA with avian myeloblastosis virus reverse transcriptase (Takara Bio Inc., Otsu, Japan). PCR amplification was conducted using SYBR Premix EX Taq (Takara). Amplification and detection were performed with the StepOneplus Real-Time PCR System (Thermo Fisher Scientific, Carlsbad, CA). The thermal cycling program was as follows: 10 -second denaturation steps at $95^{\circ} \mathrm{C}$, followed by 50 cycles of 5 -second denaturation steps at $95^{\circ} \mathrm{C}$, and 34 -second annealing steps at $60^{\circ} \mathrm{C}$. After the reaction, dissociation curve analyses were performed to confirm the amplification of a single PCR product. Changes in gene expression were calculated using the comparative threshold cycle $(\mathrm{Ct})$ method. Ct values were first normalized by subtracting the $\mathrm{Ct}$ value obtained from $\beta$-actin (control). The sequences of primers used in the present study are listed in Table 1.

Assay for Glycerol-3-Phosphate Acyltransferase. One portion of the perfused liver was homogenized in four volumes of $0.25 \mathrm{M}$ sucrose/1 mM EDTA per $10 \mathrm{mM}$ Tris-HCl buffer (pH 7.4). Hepatic microsomes were prepared by sequential centrifugation as previously described (Karahashi et al., 2013b), and protein was assessed using a previously reported method (Lowry et al., 1951) with BSA as the standard. The activities of glycerol-3-phosphate acyltransferase (GPAT) in microsomes were assessed by the reported method 
A

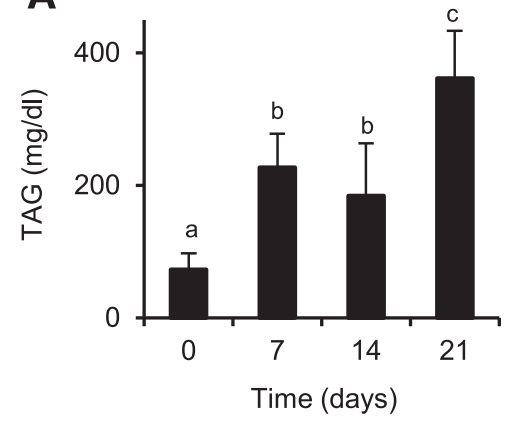

B

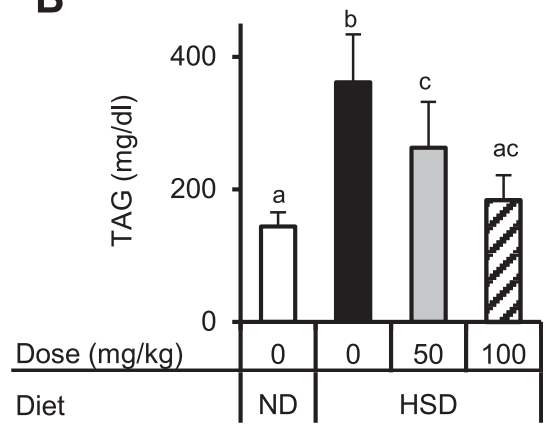

Fig. 2. Effects of HSD on serum TAG levels (A) and effects of F81-1144b on serum TAG levels in HSD-fed rats (B). (A) Rats were maintained on HSD for the indicated periods of time. (B) Rats were maintained on ND or HSD for 21 days. HSD-fed rats subcutaneously received F81-1144b at a dose of 0,50 , or $100 \mathrm{mg} / \mathrm{kg}$ once a day for 7 days before being killed. Data are presented

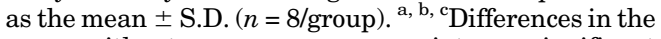
mean without a common superscript are significant $(P<0.05)$. HSD, high sucrose diet; ND, normal diet.
(Yamada and Okuyama, 1978). In brief, the assay mixture consisted of $2 \mathrm{mM}(9.26 \mathrm{kBq} / \mathrm{ml})$ [U- ${ }^{14} \mathrm{C}$ ]glycerol-3-phosphate, $40 \mu \mathrm{M}$ palmitoyl$\mathrm{CoA}, 0.5 \mathrm{mg} / \mathrm{ml}$ of BSA (essentially FA free), $0.1 \mathrm{M}$ Tris-HCl ( $\mathrm{pH} 7.5$ ), and $200 \mu \mathrm{g} / \mathrm{ml}$ of microsomal proteins. Incubations were performed at $25^{\circ} \mathrm{C}$ for 2 minutes. Lipids were extracted with chloroform/methanol after acidification of the incubation mixture with $0.1 \mathrm{M} \mathrm{HCl}$. Extracted lipids were mixed with scintillation fluid after drying down, and radioactivity was measured.

Statistical Analysis. Data are presented as the mean \pm S.D. The homogeneity of variance was established using a one-way analysis of variance. When a difference was significant $(P<0.05)$, Scheffé multiple range test was used as a post-hoc test. Levels of significance were set at $P<0.05$. The significance of differences between two groups was analyzed using the Student $t$ test.

\section{Results}

Effects on Serum TAG Levels in HSD-Fed Rats. It was initially confirmed that feeding HSD causes hypertriglyceridemia. When rats were fed HSD, serum TAG levels gradually increased by as much as 4 -fold on day 21 (Fig. 2A). To estimate the effects of F81-1144b on serum TAG levels, rats maintained on HSD for 21 days were subcutaneously administered F81-1144b once a day for 7 days at doses of 50 or $100 \mathrm{mg} / \mathrm{kg}$ before being killed, and biochemical and physiologic parameters were measured. Elevations in serum TAG levels by the feeding of HSD significantly decreased in a dose-dependent manner following the treatment of rats with F81-1144b, and TAG levels in the F81-1144b dosing group at a dose of $100 \mathrm{mg} / \mathrm{kg}$ were similar to those in ND-fed control rats (Fig. 2B). The feeding of HSD did not affect body weight, and the treatment with F81-1144b at a dose of $100 \mathrm{mg} / \mathrm{kg}$ insignificantly reduced body weight (Table 2). No significant changes were noted in the overall health of rats following the administration of F81-1144b $(100 \mathrm{mg} / \mathrm{kg})$. The feeding of HSD slightly increased liver weights and relative liver weights. Serum levels of cholesterol were markedly elevated by the feeding of HSD, and these increases were reduced by F81-1144b in a dose-dependent manner. Serum levels of glucose slightly increased upon the feeding of HSD; these levels returned to normal values following the treatment of rats with F81-1144b. The treatment with F81-1144b at a dose of 50 or $100 \mathrm{mg} / \mathrm{kg}$ significantly suppressed the serum levels of TAG, but not glucose, in rats that were maintained on the normal diet (Supplemental Fig. 1, A and B).

Effects on the Expression of Genes Related to VLDL Formation and Degradation. Regarding VLDL degradation, HSD feeding tended to downregulate the expression of genes for LPL (Student $t$ test, $P=0.0075$, ND vs. HSD-fed control), and significantly upregulated that for apolipoprotein (apo) CIII (Fig. 3, A and B). The administration of F81-1144b to rats maintained on HSD significantly increased the expression of $\mathrm{Lpl}$ in a dose-dependent manner, and markedly reduced the elevated levels of mRNA for Apoc3 in a dosedependent manner to the levels of ND-fed control rats (Fig. 3, $\mathrm{A}$ and B). When ND-fed rats were treated with F81-1144b, the expression of $L p l$ was upregulated and that of Apoc3 was downregulated (Supplemental Fig. 1, C and D). Regarding the formation of VLDL, HSD feeding markedly upregulated the expression of gene encoding lipin 1 , and significantly elevated the levels of mRNAs for microsomal triglyceride transfer protein (MTP) and Apo-CIII (Fig. 3, B-D). F81-1144b dosing little affected the expression of $M t p$, but markedly lowered that of Apoc3 and Lipin1 in a dose-dependent manner to the levels of ND-fed control rats (Fig. 3, B-D). The expression of gene for Apo-AI, the main component of high density lipoprotein, was little affected by HSD feeding, and markedly elevated by F81-1144b dosing (Fig. 3E).

Effects on VLDL-TAG Secretion in HSD-Fed Rats in the Fed State. To estimate the effects of F81-1144b on the secretion of VLDL-TAG that formed in the liver, $\left[{ }^{3} \mathrm{H}\right]$ glycerol was injected into the portal vein and Triton WR-1339 was injected into the tail vein of HSD-fed control rats and in HSD-fed rats treated with F81-1144b. $\left[{ }^{3} \mathrm{H}\right] \mathrm{TAG}$ that appeared in serum was then measured (Fig. 4). It is important to note that this experiment was performed in the fed state to avoid the influence of fasting. No marked differences were observed in diet intake between control and F81-1144b-treated rats (Supplemental Fig. 2A). $\left[{ }^{3} \mathrm{H}\right] \mathrm{TAG}$ that appeared in the circulation was markedly less in F81-1144b-treated rats than in HSD-fed control rats (Fig. 4A). The $\left[{ }^{3} \mathrm{H}\right] \mathrm{TAG}$ secretion rate, which was calculated between 0 and 60 minutes, was reduced by $45 \%$ with F81-1144b dosing (Fig. 4B).

Effects on TAG Metabolism in the Liver of HSD-Fed Rats. The administration of F81-1144b to HSD-fed rats significantly reduced hepatic TAG levels without affecting hepatic phospholipid contents (Fig. 5, A and B). F81-1144b dosing markedly changed the FA profile (mol \%) of TAG and phospholipids in the liver (Supplemental Table 1). F81-1144b at a dose of $100 \mathrm{mg} / \mathrm{kg}$ reduced the proportions of palmitic, palmitoleic, stearic, and octadecenoic acids, but increased those of linoleic, 8, 11, 14-eicosatrienoic, and arachidonic acids in TAG. However, the treatment with F81-1144b reduced the proportions of octadecenoic, $\alpha$-linolenic, and 5, 8, 11-eicosatrienoic acids in phospholipids. When these results were compared by the differences in the content (micromoles per gram liver) of a particular FA between HSD-fed control 
TABLE 2

Effects of F81-1144b on physiologic and serum measurements of HSD-fed rats

Values are represented as the mean \pm S.D. $(n=10$ /group). Rats were maintained on the ND or HSD for 21 days. HSD-fed rats subcutaneously received F81-1144b at a dose of 0,50 , or $100 \mathrm{mg} / \mathrm{kg}$ once a day for 7 days before being killed.

\begin{tabular}{lrcrc}
\hline & \multicolumn{1}{c}{ ND } & \multicolumn{1}{c}{ HSD } \\
\hline Dosage of F81-1144b (mg/kg) & 0 & 0 & 50 & 100 \\
Body weight (g) & $266.2 \pm 8.8^{a}$ & $274.5 \pm 10.6^{a}$ & $261.7 \pm 8.0^{a, b}$ & $253.0 \pm 7.3^{b}$ \\
Liver weight (g) & $10.79 \pm 0.48^{a}$ & $13.35 \pm 1.25^{b}$ & $13.99 \pm 1.1^{b}$ & $14.13 \pm 0.97^{b}$ \\
Relative liver weight (\% body weight) & $4.05 \pm 0.11^{a}$ & $4.86 \pm 0.35^{b}$ & $5.35 \pm 0.41^{c}$ & $5.58 \pm 0.32^{c}$ \\
Serum & & & & \\
$\quad$ Cholesterol (mg/dl) & $47.39 \pm 2.66^{a}$ & $75.16 \pm 12.42^{b}$ & $67.98 \pm 8.56^{b}$ & $49.89 \pm 7.94^{a}$ \\
$\quad$ Glucose (mg/dl) & $143.6 \pm 8.2^{a}$ & $170.9 \pm 29.1^{b}$ & $142.7 \pm 4.5^{a}$ & $146.3 \pm 6.0^{a}$ \\
\hline
\end{tabular}

HSD, high sucrose diet; ND, normal diet.

${ }_{a, b}{ }^{2}$ Differences in the mean without a common superscript are significant $(P<0.05)$. In the absence of a superscript, the difference in the means is not significant $(P>0.05)$.

rats and HSD-fed rats receiving $100 \mathrm{mg} / \mathrm{kg}$ of $\mathrm{F} 81-1144 \mathrm{~b}$ (Fig. 5, C and D), the differences in the masses of de novo synthesized FAs (palmitic, octadecenoic, palmitoleic, and stearic acids) in TAG were significantly decreased (Fig. 5C); changes in the differences in the masses of these FAs in phospholipids were less prominent than those in TAG (Fig. 5D). The changes caused by $50 \mathrm{mg} / \mathrm{kg}$ of F81-1144b in profiles $(\mathrm{mol} \%)$ and differences in the masses of de novo synthesized FAs were less than those induced by $100 \mathrm{mg} / \mathrm{kg}$ of F81-1144b.

To gain insights into the molecular basis for understanding the reduction in hepatic TAG by F81-1144b, the mRNA levels of key enzymes and proteins involved in the synthesis of FA and TAG were measured (Fig. 6; Supplemental Table 2). The expression of genes for fatty acid synthase (FAS) was markedly upregulated by the feeding of HSD, and the elevated expression was suppressed by F81-1144b dosing in a dose-dependent manner (Fig. 6A). The treatment of ND-fed rats with F81-1144b tended to suppress hepatic expression of Fas (Scheffé multiple range test, $P=0.0551$, control vs. group receiving $100 \mathrm{mg} / \mathrm{kg}$ ) (Supplemental Fig. $1 \mathrm{E})$. The levels of mRNA of Fas in HSD-fed rats receiving $100 \mathrm{mg} / \mathrm{kg}$ of F81-1144b were similar to those in ND-fed control rats receiving F81-1144b at a dose of $100 \mathrm{mg} / \mathrm{kg}$.

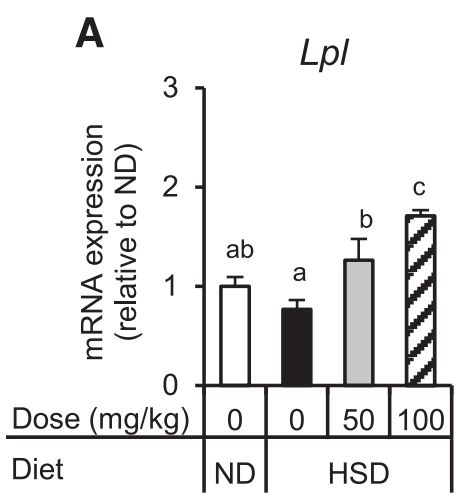

D

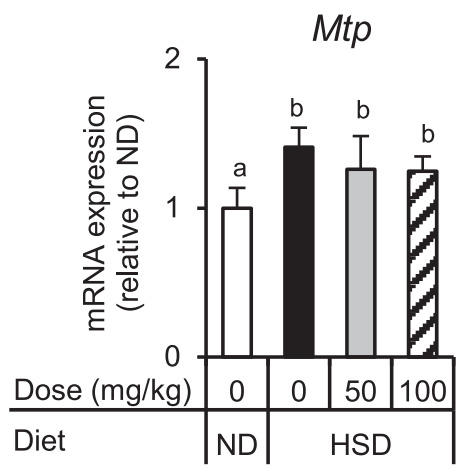

B

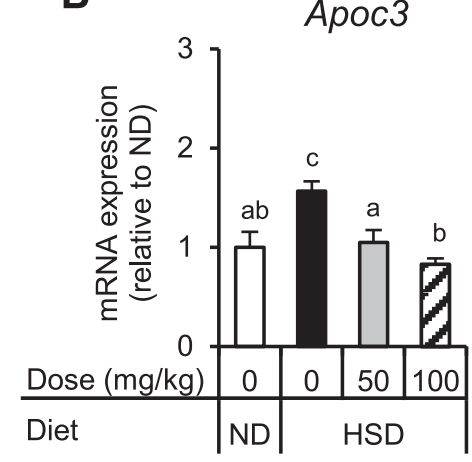

E

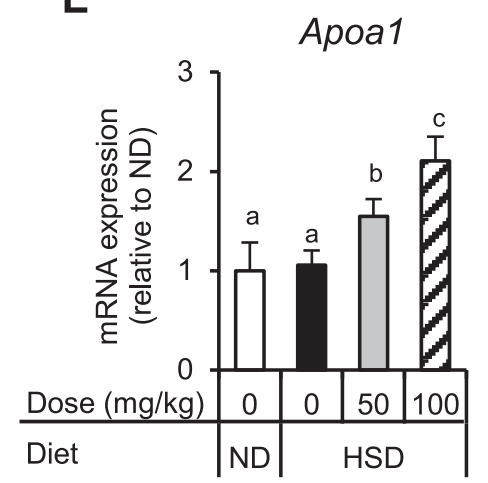

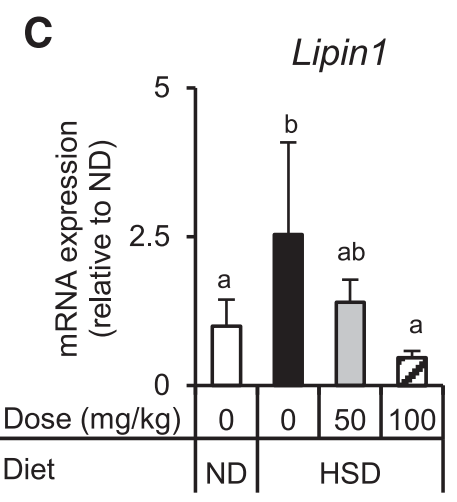

Fig. 3. Effects of F81-1144b on the expression of genes related to VLDL formation and degradation. Rats were maintained on ND or HSD for 21 days. HSD-fed rats subcutaneously received F81-1144b at a dose of 0,50 , or $100 \mathrm{mg} / \mathrm{kg}$ once a day for 7 days before being killed. (A) $\mathrm{Lpl}$ (lipoprotein lipase), (B) Apoc3 (apolipoprotein CIII), (C) Lipin1 (lipin 1), (D) Mtp (microsomal triglyceride transfer protein), (E) Apoa1 (apolipoprotein AI). The levels of mRNA in liver of HSD-fed rats relative to those in liver of ND-fed control rats are presented as the mean \pm S.D. $(n=6 /$ group $)$. ${ }^{\text {, } b, ~}{ }^{c}$ Differences in the mean without a common superscript are significant $(P<0.05)$. 


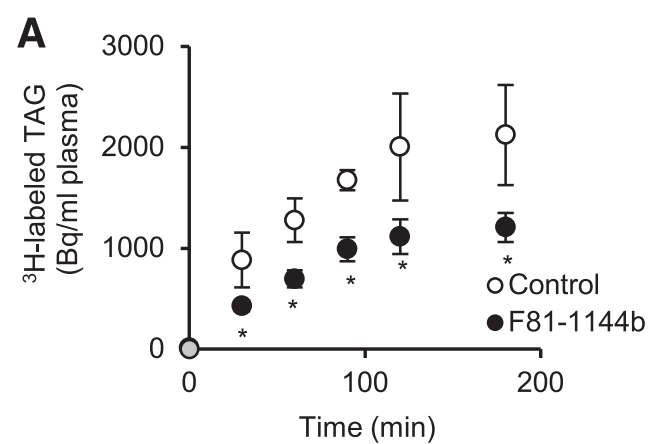

B

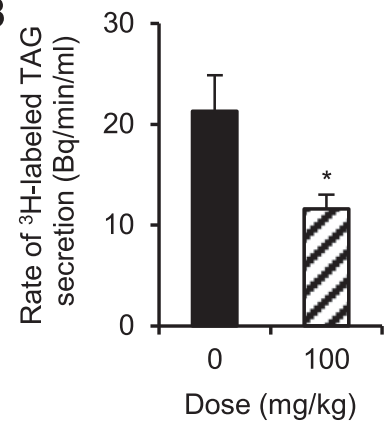

Fig. 4. Effects of F81-1144b on VLDL-TAG secretion in HSD-fed rats in the fed state. Rats that were maintained on HSD for 21 days were subcutaneously administered F81-1144b at a dose of 0 or $100 \mathrm{mg} / \mathrm{kg}$ once a day for 7 days before measuring VLDL-TAG secretion. Rats were administered $\left[{ }^{3} \mathrm{H}\right]$ glycerol via the portal vein, and Triton WR1339 was injected via the tail vein 15 minutes later. A blood sample was collected 1 minute before and 30,60, and 120 minutes after the Triton WR1339 injection. The incorporation of radioactivity into plasma TAG was measured. (A) Timecourse of the appearance of $\left[{ }^{3} \mathrm{H}\right] \mathrm{TAG}$ in plasma. (B) The rate of $\left[{ }^{3} \mathrm{H}\right] \mathrm{TAG}$ secretion between 0 and 60 minutes. Values are presented as the mean \pm S.D. $(n=4$ or 5/group). *Significantly different from HSD-fed control $(* P<0.05)$.

Regarding the other enzymes related to de novo FA synthesis, the expression of genes encoding acetyl-CoA carboxylase 1 (ACC1), glucose-6-phosphate dehydrogenase (G6PD), ATP-citrate lyase (ACLY), malic enzyme 1 (ME1), and stearoyl-CoA desaturase 1 (SCD1) were all significantly downregulated by the treatment of HSD-fed rats with F811144b (Supplemental Table 2). The effects of F81-1144b on de novo FA synthesis in the liver were estimated in vivo by
A

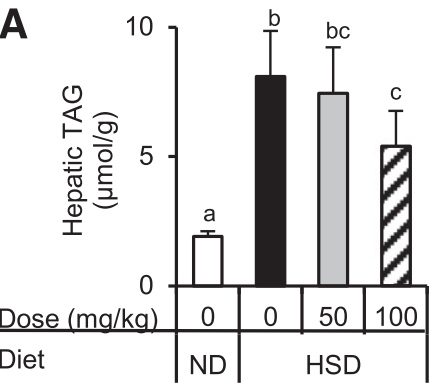

C

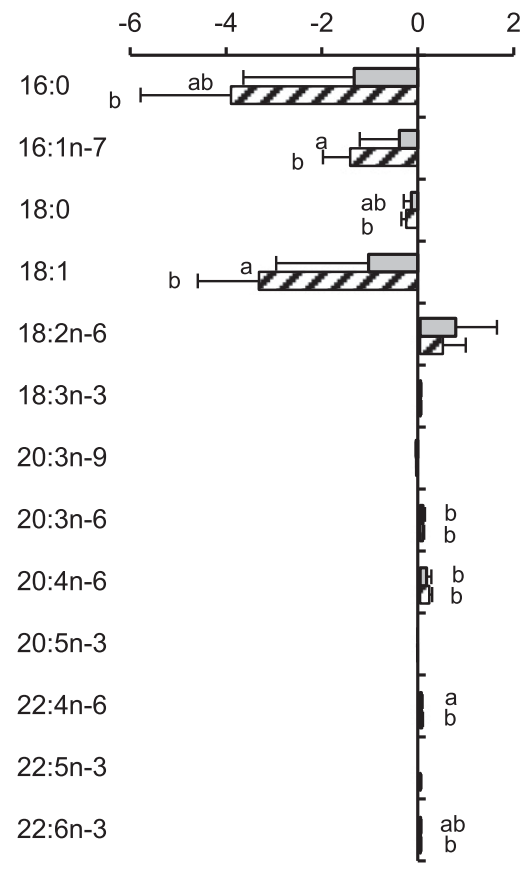

$50 \mathrm{mg} / \mathrm{kg}$

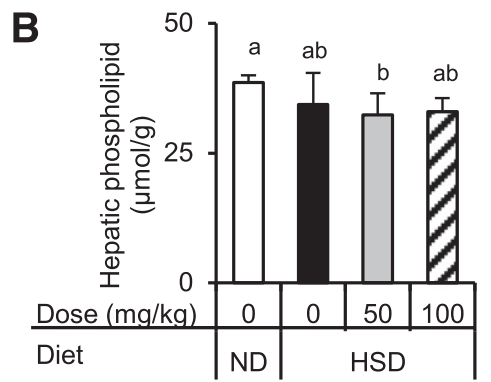

D

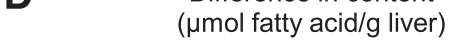

16:0

$16: 1 n-7$

18:0

18:1

$18: 2 n-6$

$18: 3 n-3$

$20: 3 n-9$

$20: 3 n-6$

$20: 4 n-6$

20:5n-3

$22: 4 n-6$

$22: 5 n-3$

$22: 6 n-3$
( $\mu \mathrm{mol}$ fatty acid/g liver)

\section{2}
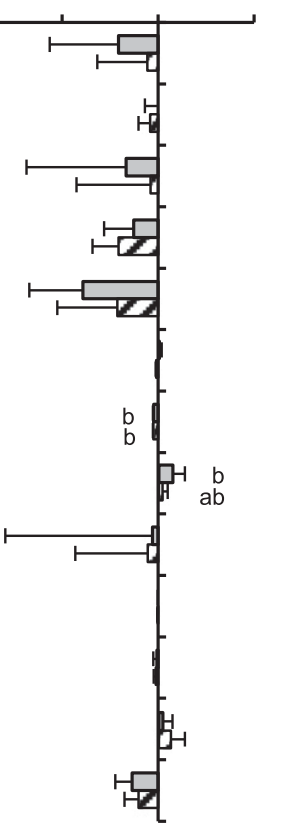

Fig. 5. Effects of F81-1144b on contents and fatty acid composition of TAG and phospholipid in liver of HSD-fed rats. Rats were maintained on ND or HSD for 21 days. HSD-fed rats subcutaneously received $\mathrm{F} 81-1144 \mathrm{~b}$ at a dose of 0,50 , or $100 \mathrm{mg} / \mathrm{kg}$ once a day for 7 days before being killed. (A) Effects of F81-1144b on TAG contents in liver of HSD-fed rats ( $n=8$ /group). (B) Effects of F81-1144b on phospholipid contents in liver of HSD-fed rats $(n=8 /$ group). (C) Differences in contents (micromoles per gram liver) of fatty acids in hepatic TAG between HSD-fed rats receiving F 81-1144b at a dose of $50 \mathrm{mg} / \mathrm{kg}$ and HSD-fed control rats and between HSD-fed rats receiving F81-1144b at a dose of $100 \mathrm{mg} / \mathrm{kg}$ and HSD-fed control rats. Regarding each fatty acid, differences in contents between the two groups were calculated from the data in Supplemental Table $1(n=$ 8/group). (D) Differences in contents (micromoles per gram liver) of fatty acids in hepatic phospholipids between HSD-fed rats receiving F81-1144b at a dose of $50 \mathrm{mg} / \mathrm{kg}$ and HSD-fed control rats and between HSD-fed rats receiving F81-1144b at a dose of $100 \mathrm{mg} / \mathrm{kg}$ and HSD-fed control rats $(n=$ 8/group). Regarding each fatty acid, differences in contents between the two groups were calculated from the data in Supplemental Table 1. Values are presented as the mean \pm S.D. ${ }^{\mathrm{a}, \mathrm{b}}$, c Differences in the mean without a common superscript are significant $(P<0.05)$. In the absence of a superscript, the difference in the means is not significant $(P>0.05)$. Fatty acids are designated by the numbers of carbon atoms and double bonds: palmitic acid, 16:0; palmitoleic acid, 16:1n-7; stearic acid, 18:0; octadecenoic acid, 18:1; linoleic acid, 18:2n-6; $\alpha$-linolenic acid, 18:3n-3; 5,8,11-eicosatrienoic acid, 20:3n-9; 8,11,14-eicosatrienoic acid, 20:3n-6; arachidonic acid, 20:4n-6; 5,8,11,14,17-eicosapentaenoic acid, 20:5n-3; 7,10,13,16,19-docosapentaenoic acid, 22:5n-3; 4,7,10,13,16,19-docosahexaenoic acid, 22:6n-3. 
A

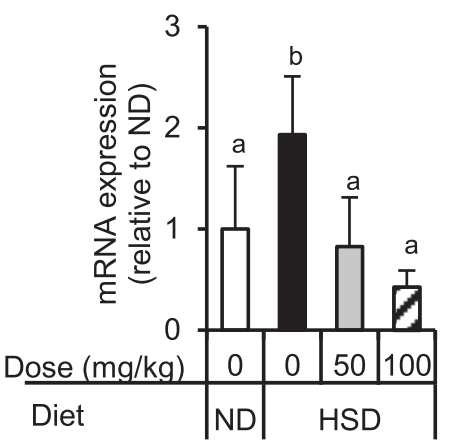

D

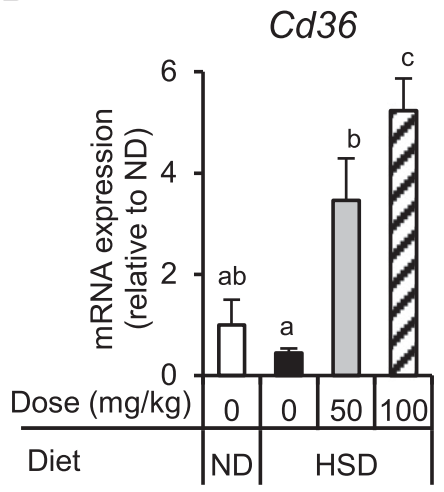

G

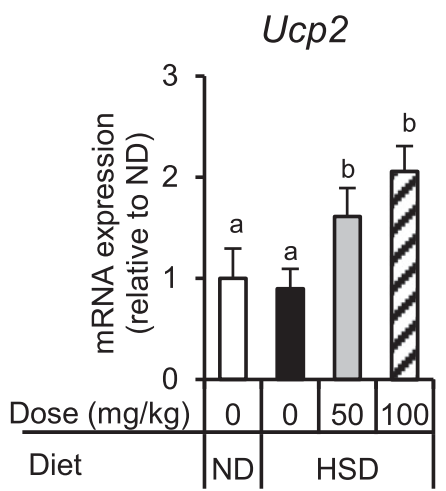

B

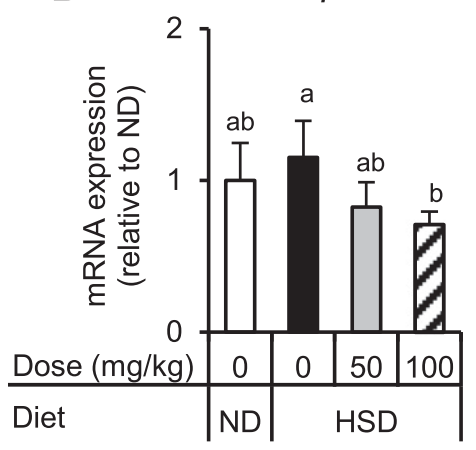

E

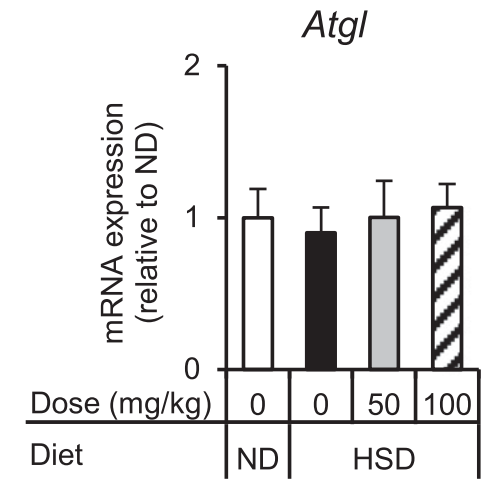

H

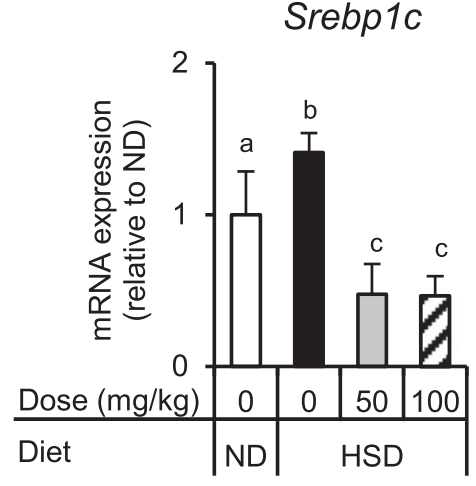

C

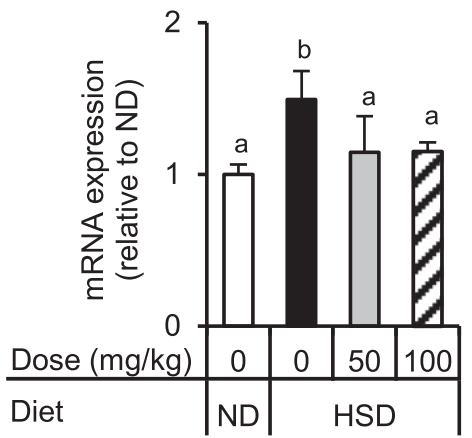

F

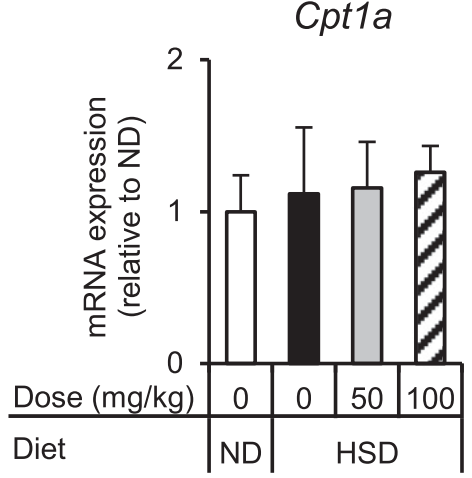

I

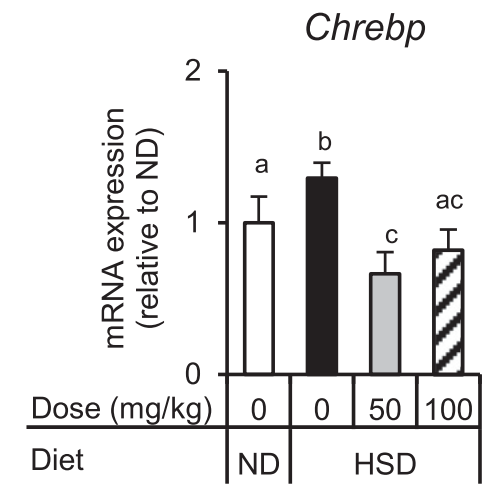

Fig. 6. Effects of F81-1144b on the expression of genes related to TAG formation and degradation in liver of HSD-fed rats. Rats were maintained on ND or HSD for 21 days. HSD-fed rats subcutaneously received F81-1144b at a dose of 0, 50, or $100 \mathrm{mg} / \mathrm{kg}$ once a day for 7 days before being killed. (A) Fas (fatty acid synthase), (B) Gpat1 (glycerol-3-phosphate acyltransferase 1), (C) Gpat4 (glycerol-3-phosphate acyltransferase 4), (D) Cd36 (fatty acid translocase), (E) Atgl (adipose triglyceride lipase), (F) Cpt1a (carnitine palmitoyltransferase 1a), (G) Ucp2 (uncoupling protein 2), (H) Srebp1c (sterol regulatory element-binding protein-1c), (I) Chrebp (carbohydrate response element-binding protein). The levels of mRNA in liver of HSD-fed rats relative to those in liver of ND-fed control rats are presented as the mean \pm S.D. $\left(n=5\right.$ or 6 /group). ${ }^{\text {a, b, }}{ }^{c}$ Differences in the mean without a common superscript are significant $(P<0.05)$. In the absence of a superscript, the difference in the means is not significant $(P>0.05)$.

measuring the incorporation of $\left[{ }^{14} \mathrm{C}\right]$ acetate, which was intraperitoneally injected, into FAs; the incorporation of $\left[{ }^{14} \mathrm{C}\right]-$ acetate into hepatic FA was significantly suppressed by the treatment with F81-1144b at a dose of $100 \mathrm{mg} / \mathrm{kg}$ (Fig. 7A). Hepatic concentrations of acetyl-CoA in rats treated with F81-1144b were slightly greater than those in HSD-fed control rats; however, the extent of the increase was only 1.27-fold (Fig. 7B). Therefore, the decrease observed in the formation of $\left[{ }^{14} \mathrm{C}\right]$-labeled FAs by F81-1144b did not appear to be the result of isotopic dilution of acetyl-CoA in the liver. F81$1144 \mathrm{~b}$ dosing markedly affected the expression of genes encoding enzymes related to glycerolipid synthesis (Fig. 6, B and C; Supplemental Table 2). The expression of gene for GPAT4 was significantly upregulated by HSD feeding; the elevated levels were suppressed by F81-1144b dosing (Fig. 6C). The activity of microsomal GPAT was increased by the feeding of HSD, and the elevated activity was significantly decreased by the treatment of rats with F81-1144b (Fig. 7C). The expression of Gpat1 was little affected by HSD feeding, whereas that in HSD-fed rats was significantly downregulated by F81-1144b dosing (Fig. 6B). The expression of genes encoding diacylglycerol acyltransferase (DGAT) 2 was suppressed by F81-1144b dosing, whereas the levels of mRNA for DGAT1 were unchanged (Supplemental Table 2). Among FA 
A

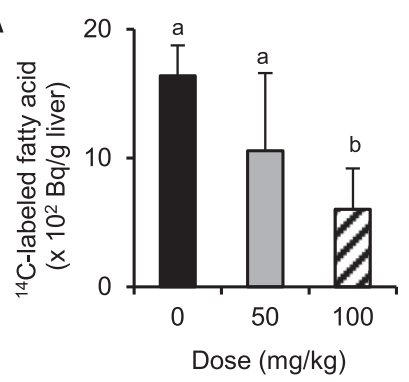

C

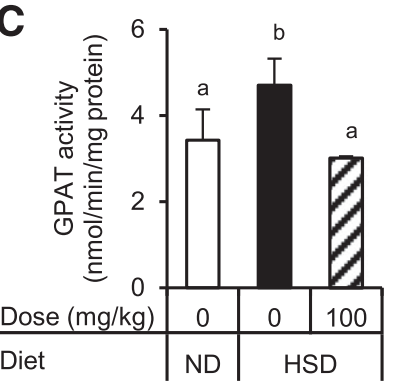

B

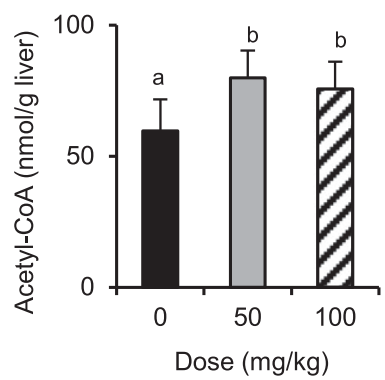

D

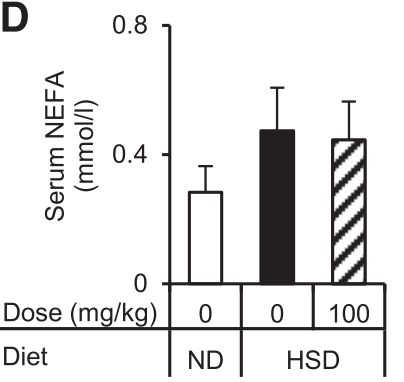

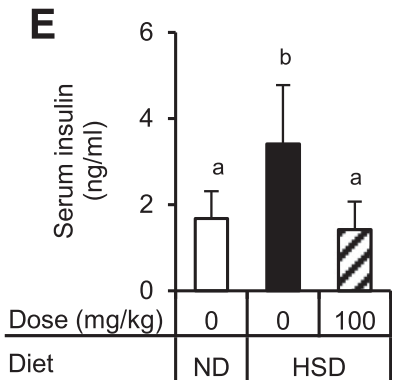

Fig. 7. Effects of F81-1144b on TAG formation in liver of HSD-fed rats. Rats were maintained on ND or HSD for 21 days. HSD-fed rats subcutaneously received F81-1144b at a dose of 0,50 , or $100 \mathrm{mg} / \mathrm{kg}$ once a day for 7 days before being killed. (A) Effects of F81-1144b on the in vivo formation of fatty acids from $\left[{ }^{14} \mathrm{C}\right]$ acetate in liver of HSD-fed rats $(n=8 /$ group). (B) Effects of F81-1144b on acetyl-CoA contents in liver of HSD-fed rats $(n=11 / \mathrm{group})$. (C) Effects of F81-1144b on microsomal activity of GPAT in liver of HSD-fed rats ( $n=4 /$ group). (D) Effects of F81-1144b on NEFA in the serum of HSD-fed rats ( $n=8 /$ group). (E) Effects of F81-1144b on insulin levels in the serum of HSD-fed rats (ND-fed control, $n=6$; HSD-fed rats, $n=12 /$ group). Values are presented as the mean \pm S.D. ${ }^{\mathrm{a}, \mathrm{b}, \mathrm{c}}$ Differences in the mean without a common superscript are significant $(P<0.05)$. In the absence of a superscript, the difference in the means is not significant $(P>0.05)$.

transporters in the liver, the expression of gene encoding fatty acid translocase (CD36) tended to be downregulated by the feeding of HSD (Student $t$ test, $P=0.0234$, ND vs. HSD-fed control), and that was markedly upregulated by the treatment of HSD-fed rats with F81-1144b in a dose-dependent manner (Fig. 6D). Fatty acid transport protein 2 was also significantly increased by the administration of F81-1144b (Supplemental Table 2). F81-1144b dosing did not change the serum levels of NEFA (Fig. 7D), and lowered the relative weight of epididymal fat (Supplemental Fig. 2B). The treatment of rats with F81-1144b significantly decreased the levels of mRNAs for long-chain acyl-CoA synthetase (ACSL) 1 and ACSL5 (Supplemental Table 2).

Regarding the effects of F81-1144b dosing on TAG catabolism in the liver, HSD feeding did not affect the expression of genes for adipose triglyceride lipase (ATGL) or carnitine palmitoyltransferase 1a (CPT1a) (Fig. 6, E and F), and the administration of F81-1144b did not upregulate the expression of genes encoding the key enzymes and proteins related to either TAG degradation (ATGL and comparative gene identification-58) or FA catabolism (CPT1a, medium-chain acyl-CoA dehydrogenase, and long-chain acyl-CoA dehydrogenase) (Fig. 6, E and F; Supplemental Table 2). The levels of mRNA encoding uncoupling protein 2 (UCP2) in the liver were not affected by the feeding of HSD, and those were markedly augmented by the treatment of HSD-fed rats with F81-1144b (Fig. 6G).

The effects of F81-1144b on the expression of genes encoding transcription factors regulating the metabolism of FA and TAG in the liver of HSD-fed rats were estimated (Fig. 6, H and I; Supplemental Table 2). The expression of gene encoding sterol regulatory element-binding protein-1c (SREBP-1c) was significantly upregulated by the feeding of HSD, and
F81-1144b dosing markedly downregulated it (Fig. 6H). Likewise, the expression of gene for carbohydrate response elementbinding protein (ChREBP) was significantly upregulated by HSD feeding, and the elevated levels were markedly decreased by F81-1144b dosing (Fig. 6I); the mRNA levels for L-type pyruvate kinase, a typical ChREBP target gene (Thompson and Towle, 1991), were reduced by F81-1144b dosing (Supplemental Table 2). The administration of F81-1144b to ND-fed rats markedly downregulated the expression of genes for these two transcription factors (Supplemental Fig. 1, F and G). The expression of the gene for peroxisome proliferator-activated receptor $\alpha(\operatorname{PPAR} \alpha)$ was suppressed by the treatment of HSD-fed rats with F81-1144b (Supplemental Table 2); nevertheless, the levels of mRNAs for acylCoA thioesterase 1, CPT1a, and ATGL, typical PPAR $\alpha$ target genes (Rakhshandehroo et al., 2010; Karahashi et al., 2013a), were unchanged (Supplemental Table 2). The feeding of HSD significantly increased serum concentrations of insulin, and the elevated levels were markedly reduced by the treatment of HSD-fed rats with F81-1144b (Fig. 7E). However, the administration of F81-1144b to streptozotocin-induced diabetic rats significantly lowered the serum levels of TAG without changing glucose concentrations (Supplemental Fig. 3).

\section{Discussion}

Overfeeding of sucrose or fructose leads to several adverse metabolic effects, including hypertriglyceridemia, hepatic steatosis, and insulin resistance (Tappy and Lê, 2010). Fructose increases the expression of lipogenic enzymes by inducing SREBP-1c and activating ChREBP, and suppresses FA oxidation by reducing PPAR $\alpha$ expression (Nagai et al., 2002; Koo et al., 2008; Softic et al., 2016), thereby favoring FA 
esterification and VLDL formation in the liver. Moreover, fructose deteriorates VLDL-TAG clearance (Hirano et al., 1989). Collectively, these metabolic changes cause hepatic steatosis and hypertriglyceridemia. The present study showed that F81-1144b reduced serum TAG levels in rats with HSD-induced hypertriglyceridemia. Two reasons have been proposed for this reduction. F81-1144b enhanced TAG degradation by LPL in plasma or suppressed VLDL-TAG secretion. Regarding VLDL-TAG metabolism in plasma, F81-1144b upregulated $\mathrm{Lpl}$ expression and downregulated Apoc3 expression in the liver. Since apo-CIII is attached to VLDL and delays VLDL breakdown by inhibiting LPL (Jong et al., 1999), the increase in $L p l$ expression and decrease in Apoc3 expression by F81-1144b appears to result in LPL activation, thereby reducing VLDL-TAG. Besides the potential effects of F81-1144b on VLDL-TAG degradation suggested by gene expression data, the present study showed that F81-1144b suppressed VLDL-TAG secretion from the liver to the circulation in rats in the HSD-fed state. The secretion rate is considered to depend not only on hepatic TAG availability, but also on the capacity for VLDL assembly. Regarding factors related to VLDL assembly, the present study showed that the expression of Lipin1 and Apoc3 in the liver was markedly downregulated by F81-1144b, but that of Mtp was not. Lipin1 positively affects the secretion pathway of TAG and apoB (Bou Khalil et al., 2010), and apo-CIII is involved in the TAG loading of VLDL (Qin et al., 2011). Moreover, the present study revealed that intrahepatic TAG was reduced by F81-1144b. Therefore, the decreased expression of Lipin1 and Apoc3 in concert with the reduced TAG supply within hepatocytes by F81-1144b may have reduced VLDL formation and secretion.

We then focused on elucidating the metabolic mechanisms underlying reductions in the hepatic TAG supply by F81-1144b. Changes in hepatic TAG concentrations occur as a result of an imbalance between lipid acquisition (de novo lipogenesis and the uptake of circulating FA) and disposal (TAG degradation and TAG export as a component of VLDL). Regarding its effects on lipogenesis, F81-1144b significantly downregulated the expression of genes encoding key enzymes (Fas, Acc1, G6pd, Acly, and Me1) related to de novo FA synthesis, strongly suggesting the suppression of de novo FA synthesis by F81-1144b. As expected, the in vivo incorporation of $\left[{ }^{14} \mathrm{C}\right]$ acetate into hepatic FAs was decreased by F81-1144b. Moreover, F81-1144b reduced the expression of Gpat1, Gpat4, Dgat2, and $S c d 1$, but not Dgat1, all of which are directly or indirectly involved in TAG synthesis. GPAT 1 and 4 are ratelimiting enzymes of TAG synthesis (Coleman and Mashek, 2011). The decrease observed in hepatic TAG levels by F81-1144b appears to be attributable to the suppressed expression of Gpat1 and/or Gpat4. GPAT1 and DGAT2 are responsible for incorporating de novo synthesized FAs into TAG (Qi et al., 2012; Wendel et al., 2013). DGAT2 appears to be linked with the esterification of monounsaturated FAs endogenously formed by SCD1 to produce TAG (Man et al., 2006). Therefore, the decreased supply of FAs formed de novo (particularly palmitic, octadecenoic, and palmitoleic acids) by fatty acid synthase and SCD1, in concert with the reduced expression of Gpat1 and Dgat2 by F81-1144b, appears to reduce TAG formation in the liver. Regarding FAs from the circulation, since F81-1144b markedly upregulated expression of $C d 36$, a transporter that mediates the uptake of circulating FAs
(Glatz et al., 2010), and did not change serum NEFA levels, the supply of exogenous FAs potentially available for TAG synthesis and/or $\beta$-oxidation within hepatocytes may have been increased by F81-1144b. GPAT4 is prone to use exogenous FAs for TAG formation (Wendel et al., 2013), and resides on the endoplasmic reticulum (Beigneux et al., 2006). Consistent with reduced Gpat4 expression by F81-1144b, it significantly suppressed microsomal GPAT activity, potentially suppressing TAG formation from circulating FAs. DGAT1 plays a greater role in esterifying exogenous FAs (Qi et al., 2012). F81-1144b markedly increased Ucp2 expression in the liver. This may ultimately help to limit TAG accumulation within hepatocytes, because TAG synthesis is an ATP-dependent process and the upregulation of Ucp2 provides hepatocytes with a mechanism to constrain ATP production (Cortez-Pinto et al., 1999). Regarding lipid degradation, ACSL5 and GPAT1 are considered to mediate FA channeling between anabolic and catabolic pathways; namely, the knockdown of Acsl5 decreased hepatic TAG secretion and increased FA oxidation (Bu and Mashek, 2010). GPAT1 is localized on outer mitochondrial membranes and channels FAs toward glycerolipids such as TAG, thereby diverting them away from CPT1amediated entry into mitochondria (Wendel et al., 2013). Therefore, the present result that F81-1144b significantly downregulated the expression of Acsl5 and Gpat1 suggests that F81-1144b enhanced FA degradation by elevating the supply of FAs available for $\beta$-oxidation, even though F81-1144b did not upregulate the expression of genes for the enzymes related directly to TAG degradation (Atgl) and FA $\beta$-oxidation (Cpt1a and Acsl1) (Coleman and Mashek, 2011; Lee et al., 2011).

The changes induced in the hepatic expression of key regulatory genes related to gluconeogenesis and de novo lipogenesis by fructose overfeeding are largely similar to those induced by a leptin deficiency (Shimomura et al., 2000; Koo et al., 2008). This state produces a vicious cycle of coexisting insulin resistance [overproduction of glucose owing to resistance to the normal actions of insulin through the downregulation of insulin receptor substrate (IRS)-2] and insulin sensitivity (elevated lipogenesis owing to the continuous stimulation of SREBP-1c production by insulin signals through IRS-1). Since HSD causes hepatic insulin resistance (Tappy and Lê, 2010) and the elevated expression of many lipogenic genes (Softic et al., 2016), HSD-fed rats may be in a state of coexisting insulin resistance and insulin sensitivity, as reported in leptin-deficient mice. F81-1144b dosing to HSD-fed rats decreased the hepatic expression of Srebp1c and serum insulin levels; these changes subsequently suppressed the expression of genes (Fas, Acc1, G6pd, Acly, Me1, Scd1, Gpat1, Acsl1, and Acsl5) related to FA and TAG metabolism, because these genes are known to be regulated by insulin (Ning et al., 2011; Xu et al., 2013; Grevengoed et al., 2014). These results imply that F81-1144b ameliorates dysfunctions in responses to insulin in HSD-fed rats. It is noteworthy that F81-1144b decreased serum TAG levels without changing serum glucose levels in streptozotocin-induced diabetic rats. Moreover, SREBP-1c induction and subsequent elevations in the expression of genes for key lipogenic enzymes in the liver were shown to be independent of insulin in streptozotocin-treated mice (Matsuzaka et al., 2004). Therefore, the effects of F81-1144b on TAG metabolism in the liver and plasma in HSD-fed rats may be secondary, at least in part, to its effects on insulin, and another 
mechanism, which is independent of insulin, may operate for the metabolic changes induced in lipids by F81-1144b.

Fibrates, niacin, and $n-3$ FAs are typical tools in interventions to reduce serum TAG (Ito, 2015). Fibrates facilitate lipid degradation (increased expression of Atgl and Cpt1a) in the liver by stimulating $\operatorname{PPAR} \alpha$ (Staels et al., 1998; Rakhshandehroo et al., 2010; Karahashi et al., 2013a), thereby decreasing VLDL secretion; fibrates also promote VLDL lipolysis by elevating $L p l$ expression and suppressing Apoc3 expression (Chapman et al., 2011). Niacin inhibits FA mobilization from adipose tissue and DGAT2 activities in the liver, decreasing VLDL secretion (Karpe and Frayn, 2004; Kamanna and Kashyap, 2008). $n$-3 FAs activate PPAR $\alpha$ and suppress SREBP-1c, resulting in the stimulation of FA $\beta$-oxidation and inhibition of lipogenesis, and also block the accumulation of apo-CIII on VLDL, potentially increasing lipolysis by LPL (Chapman et al., 2011; Shearer et al., 2012). Consequently, the mechanisms underlying the effects of F81-1144b may differ markedly from those of fibrates, niacin, and $n-3$ FAs.

In conclusion, the present study revealed that $\mathrm{F} 81-1144 \mathrm{~b}$ upregulated $L p l$ expression, downregulated Apoc3 expression, and suppressed VLDL-TAG secretion, which may reduce serum TAG. The reductions observed in VLDL-TAG secretion may be the result of downregulated expression of Lipin1 and Apoc3, key factors required in VLDL assembly, and/or reduced hepatic TAG levels. Decreases in intrahepatic TAG appear to be due to the reduced de novo synthesis of FAs and TAG through the suppressed expression of SREBP-1c and ChREBP in the liver. Reductions of serum insulin by F81-1144b are at least partly responsible for the observed suppression of Srebp1c expression; other mechanisms underlying the metabolic alterations induced by $\mathrm{F} 81-1144 \mathrm{~b}$ remain to be elucidated. Although F81-1144b did not affect the expression of genes (Atgl and Cpt1a) related to the degradation of TAG and FAs, but upregulated Ucp2 expression, it significantly decreased the expression of Gpat1 and Acsl5 and markedly increased $C d 36$ expression, changes that may consequently augment FA availability for $\beta$-oxidation. These potential metabolic changes induced by F81-1144b would markedly differ from those induced by fibrates, niacin, or $n-3$ FAs. These results suggest that F81-1144b and its analogs reported in our previous study (Morikawa et al., 2007) are a novel type of therapeutic agent for the treatment of hypertriglyceridemia.

\section{Acknowledgments}

The authors acknowledge Dr. Tadanori Morikawa and Ishinori Shimizu (Daiichi Fine Chemical Co., Ltd.) for helpful suggestions in the study design and continuous encouragement. They are grateful to Dr. Takashi Tanikawa and Shingo Yamada (Josai University) for technical assistance.

\section{Authorship Contributions}

Participated in research design: Kudo, Kawai, Kawashima.

Conducted experiments: Eguchi, Yamazaki, Karahashi.

Performed data analysis: Kudo, Karahashi, Kawashima.

Wrote or contributed to the writing of the manuscript: Kudo, Kawashima.

\section{References}

Adiels M, Olofsson SO, Taskinen MR, and Borén J (2008) Overproduction of very lowdensity lipoproteins is the hallmark of the dyslipidemia in the metabolic syndrome. Arterioscler Thromb Vasc Biol 28:1225-1236.

Beigneux AP, Vergnes L, Qiao X, Quatela S, Davis R, Watkins SM, Coleman RA, Walzem RL, Philips M, Reue K, et al. (2006) Agpat6-a novel lipid biosynthetic gene required for triacylglycerol production in mammary epithelium. $J$ Lipid Res 47: 734-744.

Berneis KK and Krauss RM (2002) Metabolic origins and clinical significance of LDL heterogeneity. J Lipid Res 43:1363-1379.

Bligh EG and Dyer WJ (1959) A rapid method of total lipid extraction and purification. Can J Biochem Physiol 37:911-917.

Bou Khalil M, Blais A, Figeys D, and Yao Z (2010) Lipin - the bridge between hepatic glycerolipid biosynthesis and lipoprotein metabolism. Biochim Biophys Acta 1801: $1249-1259$

Boullart ACI, de Graaf J, and Stalenhoef AF (2012) Serum triglycerides and risk of cardiovascular disease. Biochim Biophys Acta 1821:867-875.

$\mathrm{Bu}$ SY and Mashek DG (2010) Hepatic long-chain acyl-CoA synthetase 5 mediates fatty acid channeling between anabolic and catabolic pathways. J Lipid Res 51: 3270-3280.

Chapman MJ, Ginsberg HN, Amarenco P, Andreotti F, Borén J, Catapano AL, Descamps OS, Fisher E, Kovanen PT, Kuivenhoven JA, et al.; European Atherosclerosis Society Consensus Panel (2011) Triglyceride-rich lipoproteins and highdensity lipoprotein cholesterol in patients at high risk of cardiovascular disease: evidence and guidance for management. Eur Heart $J$ 32:1345-1361.

Chatrath H, Vuppalanchi R, and Chalasani N (2012) Dyslipidemia in patients with nonalcoholic fatty liver disease. Semin Liver Dis 32:22-29.

Coleman RA and Mashek DG (2011) Mammalian triacylglycerol metabolism: synthesis, lipolysis, and signaling. Chem Rev 111:6359-6386.

Cortez-Pinto H, Zhi Lin H, Qi Yang S, Odwin Da Costa S, and Diehl AM (1999) Lipids up-regulate uncoupling protein 2 expression in rat hepatocytes. Gastroenterology 116:1184-1193.

Decker K (1985) Acetyl-coenzyme A, in Methods of Enzymatic Analysis (Bremer J ed) vol 7, Wiley-Blackwell, New York.

Fruchart JC, Sacks F, Hermans MP, Assmann G, Brown WV, Ceska R, Chapman MJ, Dodson PM, Fioretto P, Ginsberg HN, et al. (2008) The Residual Risk Reduction Initiative: a call to action to reduce residual vascular risk in patients with dyslipidemia. Am J Cardiol 102 (10 Suppl):1K-34K.

Fujisawa T, Kotake S, Hongo K, Ito H, Otani M, Yasuda J, and Morikawa T (Feb 27, 2001) inventors, Jpn Kokai Tokkyo Koho (Japanese Unexamined Patent Application Publication), assignee. Metalloproteinase inhibitors containing hydroxamic acids. JP $2001055327 \mathrm{~A}$

Glatz JFC, Luiken JJFP, and Bonen A (2010) Membrane fatty acid transporters as regulators of lipid metabolism: implications for metabolic disease. Physiol Rev 90:367-417.

Grevengoed TJ, Klett EL, and Coleman RA (2014) Acyl-CoA metabolism and partitioning. Annu Rev Nutr 34:1-30.

Harchaoui KE, Visser ME, Kastelein JJ, Stroes ES, and Dallinga-Thie GM (2009) Triglycerides and cardiovascular risk. Curr Cardiol Rev 5:216-222.

Hirano T, Mamo JC, Poapst ME, Kuksis A, and Steiner G (1989) Impaired very lowdensity lipoprotein-triglyceride catabolism in acute and chronic fructose-fed rats. Am J Physiol 256:E559-E565.

Imai K, Koyama M, Kudo N, Shirahata A, and Kawashima Y (1999) Increase in hepatic content of oleic acid induced by dehydroepiandrosterone in the rat. Biochem Pharmacol 58:925-933.

Ito MK (2015) Long-chain omega-3 fatty acids, fibrates and niacin as therapeutic options in the treatment of hypertriglyceridemia: a review of the literature. Atherosclerosis 242:647-656.

Jong MC, Hofker MH, and Havekes LM (1999) Role of ApoCs in lipoprotein metabolism: functional differences between ApoC1, ApoC2, and ApoC3. Arterioscler Thromb Vasc Biol 19:472-484.

Kamanna VS and Kashyap ML (2008) Mechanism of action of niacin. Am J Cardiol 101 (8A):20B-26B

Karahashi M, Hoshina M, Yamazaki T, Sakamoto T, Mitsumoto A, Kawashima Y, and Kudo N (2013a) Fibrates reduce triacylglycerol content by upregulating adipose triglyceride lipase in the liver of rats. J Pharmacol Sci 123:356-370.

Karahashi M, Ishii F, Yamazaki T, Imai K, Mitsumoto A, Kawashima Y, and Kudo N (2013b) Up-regulation of stearoyl-CoA desaturase 1 increases liver MUFA content in obese Zucker but not Goto-Kakizaki rats. Lipids 48:457-467.

Karpe F and Frayn KN (2004) The nicotinic acid receptor-a new mechanism for an old drug. Lancet 363:1892-1894.

Kearney PM, Blackwell L, Collins R, Keech A, Simes J, Peto R, Armitage J, and Baigent C; Cholesterol Treatment Trialists' (CTT) Collaborators (2008) Efficacy of cholesterol-lowering therapy in 18,686 people with diabetes in 14 randomised trials of statins: a meta-analysis. Lancet 371:117-125.

Koo H-Y, Wallig MA, Chung BH, Nara TY, Cho BHS, and Nakamura MT (2008) Dietary fructose induces a wide range of genes with distinct shift in carbohydrate and lipid metabolism in fed and fasted rat liver. Biochim Biophys Acta 1782:341-348.

Langsted A, Freiberg JJ, Tybjaerg-Hansen A, Schnohr P, Jensen GB, and Nordestgaard BG (2011) Nonfasting cholesterol and triglycerides and association with risk of myocardial infarction and total mortality: the Copenhagen City Heart Study with 31 years of follow-up. J Intern Med 270:65-75.

Lee K, Kerner J, and Hoppel CL (2011) Mitochondrial carnitine palmitoyltransferase 1a (CPT1a) is part of an outer membrane fatty acid transfer complex. J Biol Chem 286:25655-25662.

Lowry OH, Rosebrough NJ, Farr AL, and Randall RJ (1951) Protein measurement with the Folin phenol reagent. J Biol Chem 193:265-275.

Man WC, Miyazaki M, Chu K, and Ntambi J (2006) Colocalization of SCD1 and DGAT2: implying preference for endogenous monounsaturated fatty acids in triglyceride synthesis. J Lipid Res 47:1928-1939.

Matsuzaka T, Shimano H, Yahagi N, Amemiya-Kudo M, Okazaki H, Tamura Y, Iizuka Y, Ohashi K, Tomita S, Sekiya M, et al (2004) Insulin-independent in duction of sterol regulatory element-binding protein-1c expression in the livers of streptozotocin-treated mice. Diabetes 53:560-569.

Millar JS, Cromley DA, McCoy MG, Rader DJ, and Billheimer JT (2005) Determining hepatic triglyceride production in mice: comparison of poloxamer 407 with Triton WR-1339. J Lipid Res 46:2023-2028. 
Miller M, Stone NJ, Ballantyne C, Bittner V, Criqui MH, Ginsberg HN, Goldberg AC, Howard WJ, Jacobson MS, Kris-Etherton PM, et al.; American Heart Association Clinical Lipidology, Thrombosis, and Prevention Committee of the Council on Nutrition, Physical Activity, and Metabolism; Council on Arteriosclerosis, Thrombosis and Vascular Biology; Council on Cardiovascular Nursing; Council on the Kidney in Cardiovascular Disease (2011) Triglycerides and cardiovascula disease: a scientific statement from the American Heart Association. Circulation 123:2292-2333.

Morikawa T, Toyama T, Kudo N, and Kawashima Y (2007) Reducing effect of matrix metalloproteinase inhibitors on serum triacylglycerol in streptozotocin-induced diabetic rats and Zucker fa/fa rats. Biol Pharm Bull 30:1461-1467.

Nagai Y, Nishio Y, Nakamura T, Maegawa H, Kikkawa R, and Kashiwagi A (2002) Amelioration of high fructose-induced metabolic derangements by activation of PPARalpha. Am J Physiol Endocrinol Metab 282:E1180-E1190.

Neil HA, Cooper J, Betteridge DJ, Capps N, McDowell IF, Durrington PN, Seed M, Mann JI, and Humphries SE; Simon Broome Familial Hyperlipidaemia Register Group (2010) All-cause and cardiovascular mortality in treated patients with severe hypertriglyceridaemia: a long-term prospective registry study. Atherosclerosis 211:618-623.

Ning J, Hong T, Yang X, Mei S, Liu Z, Liu H-Y, and Cao W (2011) Insulin and insulin signaling play a critical role in fat induction of insulin resistance in mouse. Am J Physiol Endocrinol Metab 301:E391-E401.

Nordestgaard BG (2016) Triglyceride-rich lipoproteins and atherosclerotic cardiovascular disease: new insights from epidemiology, genetics, and biology. Circ Res 118:547-563.

Nordestgaard BG and Varbo A (2014) Triglycerides and cardiovascular disease. Lancet 384:626-635.

Nordestgaard BG, Wootton R, and Lewis B (1995) Selective retention of VLDL, IDL, and LDL in the arterial intima of genetically hyperlipidemic rabbits in vivo. Molecular size as a determinant of fractional loss from the intima-inner media. Arterioscler Thromb Vasc Biol 15:534-542.

Ouyang X, Cirillo P, Sautin Y, McCall S, Bruchette JL, Diehl AM, Johnson RJ, and Abdelmalek MF (2008) Fructose consumption as a risk factor for non-alcoholic fatty liver disease. J Hepatol 48:993-999.

Qi J, Lang W, Geisler JG, Wang P, Petrounia I, Mai S, Smith C, Askari H, Struble GT, Williams R, et al. (2012) The use of stable isotope-labeled glycerol and oleic acid to differentiate the hepatic functions of DGAT1 and -2. J Lipid Res $\mathbf{5 3}$ $1106-1116$

Qin W, Sundaram M, Wang Y, Zhou H, Zhong S, Chang C-C, Manhas S, Yao EF, Parks RJ, McFie PJ, et al. (2011) Missense mutation in APOC3 within the C-terminal lipid binding domain of human ApoC-III results in impaired assembly and secretion of triacylglycerol-rich very low density lipoproteins: evidence that ApoC-III plays a major role in the formation of lipid precursors within the microsomal lumen. J Biol Chem 286:27769-27780.

Rakhshandehroo M, Knoch B, Müller M, and Kersten S (2010) Peroxisome proliferator-activated receptor alpha target genes. PPAR Res 2010 DOI: 10.1155/2010/ 612089 .
Sakurai T, Miyazawa S, and Hashimoto T (1978) Effects of di-(2-ethylhexyl)phthalate administration on carbohydrate and fatty acid metabolism in rat liver. J Biochem 83:313-320. Sarwar N, Sandhu MS, Ricketts SL, Butterworth AS, Di Angelantonio E, Boekholdt SM, Ouwehand W, Watkins H, Samani NJ, Saleheen D, et al.; Triglyceride Coronary Disease Genetics Consortium and Emerging Risk Factors Collaboration (2010) Triglyceride-mediated pathways and coronary disease: collaborative analysis of 101 studies [published correction appears in Lancet (2010) 376:90]. Lancet 375:1634-1639.

Schwartz EA and Reaven PD (2012) Lipolysis of triglyceride-rich lipoproteins, vascular inflammation, and atherosclerosis. Biochim Biophys Acta 1821:858-866.

Shearer GC, Savinova OV, and Harris WS (2012) Fish oil - how does it reduce plasma triglycerides? Biochim Biophys Acta 1821:843-851.

Shimomura I, Matsuda M, Hammer RE, Bashmakov Y, Brown MS, and Goldstein JL (2000) Decreased IRS-2 and increased SREBP-1c lead to mixed insulin resistance and sensitivity in livers of lipodystrophic and ob/ob mice. Mol Cell 6:77-86.

Softic S, Cohen DE, and Kahn CR (2016) Role of dietary fructose and hepatic de novo lipogenesis in fatty liver disease. Dig Dis Sci 61:1282-1293.

Staels B, Dallongeville J, Auwerx J, Schoonjans K, Leitersdorf E, and Fruchart J-C (1998) Mechanism of action of fibrates on lipid and lipoprotein metabolism. Circulation 98:2088-2093.

Tappy L and Lê K-A (2010) Metabolic effects of fructose and the worldwide increase in obesity. Physiol Rev 90:23-46.

Taskinen MR (2003) Diabetic dyslipidaemia: from basic research to clinical practice. Diabetologia 46:733-749.

Thompson KS and Towle HC (1991) Localization of the carbohydrate response element of the rat L-type pyruvate kinase gene. J Biol Chem 266:8679-8682.

Wang YI, Schulze J, Raymond N, Tomita T, Tam K, Simon SI, and Passerini AG (2011) Endothelial inflammation correlates with subject triglycerides and waist size after a high-fat meal. Am J Physiol Heart Circ Physiol 300: H784-H791.

Wendel AA, Cooper DE, Ilkayeva OR, Muoio DM, and Coleman RA (2013) Glycerol-3phosphate acyltransferase (GPAT)-1, but not GPAT4, incorporates newly synthesized fatty acids into triacylglycerol and diminishes fatty acid oxidation. $J$ Biol Chem 288:27299-27306.

Xu X, So JS, Park JG, and Lee AH (2013) Transcriptional control of hepatic lipid metabolism by SREBP and ChREBP. Semin Liver Dis 33:301-311.

Yamada K and Okuyama H (1978) Selectivity of diacylglycerophosphate synthesis in subcellular fractions of rat liver. Arch Biochem Biophys 190:409-420.

Yamazaki T, Kadokura M, Mutoh Y, Sakamoto T, Okazaki M, Mitsumoto A Kawashima Y, and Kudo N (2014) Inducing effect of clofibric acid on stearoyl-CoA desaturase in intestinal mucosa of rats. Lipids 49:1203-1214.

Address correspondence to: Dr. Yoichi Kawashima, Faculty of Pharmacy and Pharmaceutical Sciences, Josai University, 1-1 Keyakidai, Sakado, Saitama 350-0295, Japan. E-mail: ykawash@josai.ac.jp 